\title{
Dehydrogenation of Ethylbenzene with Carbon Dioxide as Soft Oxidant over Supported Vanadium-Antimony Oxide Catalyst
}

\author{
Do-Young Hong, Vladislav P. Vislovskiy, Sang-Eon Park, ${ }^{\dagger, *}$ Min-Seok Park, ${ }^{\ddagger}$ Jin S. Yoo, and Jong-San Chang \\ Catalysis Center for Molecular Engineering, Korea Research Institute of Chemical Technology (KRICT), P.O. Box 107, \\ Yuseong, Daejeon 305-600, Korea. E-mail: jschang@krict.re.kr \\ ${ }^{\dagger}$ Department of Chemistry, Inha University, Incheon 402-751, Korea. *E-mail: separk@inha.ac.kr \\ ${ }^{\star}$ Department of Biotechnology \& Food Science, Mongolia International University, Ulaanbaatar, Mongolia
}

Received May 6, 2005

\begin{abstract}
This work presents that carbon dioxide, which is a main contributor to the global warming effect, could be utilized as a selective oxidant in the oxidative dehydrogenation of ethylbenzene. The dehydrogenation of ethylbenzene over alumina-supported vanadium-antimony oxide catalyst has been studied under different atmospheres such as inert nitrogen, steam, oxygen or carbon dioxide as diluent or oxidant. Among them, the addition of carbon dioxide gave the highest styrene yield (up to 82\%) and styrene selectivity (up to 97\%) along with stable activity. Carbon dioxide could play a beneficial role of a selective oxidant in the improvement of the catalytic behavior through the oxidative pathway.
\end{abstract}

Key Words : Carbon dioxide, Oxidant, Dehydrogenation, Ethylbenzene, Styrene

\section{Introduction}

The utilization of carbon dioxide, which is a main contributor to the greenhouse effect, has been of global interest from both fundamental and practical viewpoints in green and catalytic chemistry. ${ }^{1}$ In particular, it is worthwhile to note that carbon dioxide could be used as an oxygen source or oxidant and can be considered as a nontraditional mild oxidant and oxygen transfer agent. ${ }^{2,3}$ It has been proposed that carbon dioxide plays a role as the soft oxidant to abstract hydrogen from simple or functionalized hydrocarbons through the catalytic activation of carbon dioxide to form $\mathrm{CO}$ and oxygen species. ${ }^{4,5}$ Possible reactions are the oxidative conversions of alkanes, alkenes, alcohols ${ }^{4,6}$ and alkylaromatic hydrocarbons, especially ethylbenzene., ${ }^{5,7-21}$ The effect of carbon dioxide in the different catalytic reactions has been generalized by Centi and Perathoner as a particular case of gas-doped modification with $\mathrm{CO}_{2}$ for a catalyst surface or/and bulk composition and structure, electronic, acid-base, adsorption, diffusion and redox properties. $^{22}$ This modification can lead to the changes in a reaction mechanism, catalytic activity and product selectivity. The use of $\mathrm{CO}_{2}$ in catalytic reactions can give several advantages in catalysis such as acceleration of the reaction rate, enhancement of product selectivity, alleviation of chemical equilibrium, suppression of the total oxidation, and prevention of hot spots on catalyst surface..$^{5,7,10,23}$ Taking into account its unique characteristics, it is anticipated that this concept might lead to emerging new chemistry of carbon dioxide as the oxidant.

Styrene is commercially produced by dehydrogenation of ethylbenzene (EBDH) using potassium-promoted iron oxide catalysts with a large excess of superheated steam. Although steam is widely used in the EBDH due to several beneficial roles such as providing heat to the endothermic dehydro- genation, diluting $\mathrm{EB}$ in order to increase equilibrium conversion, and preventing coke deposition on the catalyst, the use of steam has a drawback of losing latent heat of condensation during subsequent separation particularly in a commercial process. ${ }^{24}$ As an alternative way, the oxidative dehydrogenation of EB has been proposed to be free from thermodynamic limitations regarding conversion, operating at lower temperatures with an exothermic reaction. ${ }^{25}$ However, the oxidative dehydrogenation of $\mathrm{EB}$ with oxygen as strong oxidant suffers from loss of selectivity for styrene due to the production of carbon oxides and oxygenates.

Recently, the utilization of carbon dioxide as an oxidant for the EBDH has been attempted to explore new technology for producing styrene selectively. ${ }^{5,7-21}$ Several catalyst systems were found to be efficient for the $\mathrm{CO}_{2}-\mathrm{EBDH}$ reaction. Among them V-containing catalysts, ${ }^{13-15,19-21}$ which are known to be active and selective in mild oxidation reactions, such as partial oxidation, oxidative dehydrogenation, and ammoxidation of hydrocarbons, ${ }^{23,25-35}$ including the EBDH with oxygen..$^{25,32-35}$ Obviously, the effect of carbon dioxide on the EBDH certainly depends on the nature of the catalyst used. Thus, even small amount of $\mathrm{CO}_{2}$ strongly inhibits the activity of commercial potassiumpromoted iron oxide catalyst, ${ }^{36}$ and, naturally, the activity of $\mathrm{FeO}_{\mathrm{x}}$-based catalyst system is very low in the EBDH with carbon dioxide $\left(\mathrm{CO}_{2}\right.$-EBDH). ${ }^{10,17}$ However, iron oxide supported on active carbon, alumina and NaZSM-5 zeolite is catalytically efficient in this reaction. ${ }^{10,12,16}$ At the same time, over the $\mathrm{Na}_{2} \mathrm{O} / \mathrm{Al}_{2} \mathrm{O}_{3},{ }^{37}$ chromium and cerium oxide catalysts supported on active carbon, ${ }^{14}$ the increase of styrene yield under carbon dioxide compared to that under the inert atmosphere was achieved mainly by the increase of styrene selectivity whereas ethylbenzene conversions were not changed. On $\mathrm{CrO}_{x} / \mathrm{SiO}_{2}$ catalyst, they even drop to lower values as the partial pressure of $\mathrm{CO}_{2}$ was raised above $5 \mathrm{kPa}$, 
but, in the same work, ${ }^{38}$ noticeable activation effect of $\mathrm{CO}_{2}$ on the ethylbenzene conversions was revealed over $\mathrm{CrO}_{\mathrm{x}} /$ $\mathrm{Al}_{2} \mathrm{O}_{3}$ catalyst. In a number of cases, almost solely on the supported $\mathrm{FeO}_{\mathrm{x}}{ }^{5,5,7,10-12,16,39-42}$ and $\mathrm{VO}_{\mathrm{x}}{ }^{5,13,15,21,41-45}$-based systems, the introduction of carbon dioxide into the reaction mixtures positively affects both styrene selectivity and total reaction rate as well as partly hinders the coke formation.

Previously, we reported that the alumina-supported V-Sb oxide system is highly active and selective catalyst for the $\mathrm{CO}_{2}$-EBDH. ${ }^{5,21,44,45}$ The improved catalytic behavior was attributed to the redox properties of active $\mathrm{V}$-sites enhanced by the insertion of an antimony oxide promoter. ${ }^{44,45}$ In this work, we investigate the catalytic behaviors of this system in the EBDH under different atmosphere such as nitrogen, steam, oxygen or carbon dioxide in order to clarify the effect of carbon dioxide.

\section{Experimental Section}

An alumina-supported vanadium-antimony oxide catalyst, $\mathrm{V}_{0.43} \mathrm{Sb}_{0.57} \mathrm{O}_{\mathrm{x}} / \mathrm{Al}_{2} \mathrm{O}_{3}$ (denoted as $\mathrm{VSb} / \mathrm{Al}$ ), was prepared by impregnation of activated alumina (Aldrich 19,996-6, $\mathrm{S}_{\mathrm{BET}}=$ $121 \mathrm{~m}^{2} / \mathrm{g}$ ) with aqueous solutions of ammonium metavanadate and antimony(III) chloride (Aldrich) along with tartaric acid. ${ }^{44}$ Subscript numbers of $\mathrm{V}$ and $\mathrm{Sb}$ in the formulae of $\mathrm{VSb} / \mathrm{Al}$ indicate the atomic percentages of the element in the supported binary system. The impregnated sample was dried at $120{ }^{\circ} \mathrm{C}$ and then calcined in air at $600{ }^{\circ} \mathrm{C}$ for $4 \mathrm{~h}$. The total amount of the supported oxide component was $20 \mathrm{wt} . \%$.

The calcined sample was characterized by means of BET specific surface area $\left(\mathrm{S}_{\mathrm{BET}}\right)$ measurements, $\mathrm{X}$-ray diffraction (XRD), X-ray photoelectron spectroscopy (XPS). $\mathrm{S}_{\mathrm{BET}}$ data were calculated from $\mathrm{N}_{2}$ adsorption isotherms using a Micrometrics model ASAP 2400. XRD patterns were recorded on a Rigaku D/MAX-3B diffractometer using monochromatic $\mathrm{Cu}-\mathrm{K}_{\alpha}$ radiation. The X-ray photoelectron spectra were obtained using an ESCALAB MK II spectrometer provided with a hemispherical electron analyzer and $\mathrm{Al}$ anode X-ray exciting source ( $\mathrm{Al} \mathrm{K} \alpha=1487.6 \mathrm{eV})$. The binding energies (BE) were referred to the adventitious $\mathrm{C} 1 \mathrm{~s}$ peak at $284.6 \mathrm{eV}$.

The EBDH reactions were carried out at $500-6500^{\circ} \mathrm{C}$ in a micro-activity test unit (Zeton, MAT 2000) with a fixed bed isothermal reactor under atmospheric pressure. A catalyst sample of $1 \mathrm{~g}$ was placed into reactor on a quartz wool support. EB was introduced with a feed rate of $8.2 \mathrm{mmol} / \mathrm{h}$ by a syringe pump and supplied into the reactor together with a corresponding carrier gas (oxidant). Total flow rate was $45 \mathrm{~mL} / \mathrm{min}$. Nitrogen was used as a diluent as well as an internal standard for gas analysis. Gas components of the reaction mixture $\left(\mathrm{H}_{2}, \mathrm{~N}_{2}, \mathrm{CO}, \mathrm{CH}_{4}\right.$, and $\left.\mathrm{CO}_{2}\right)$ were analyzed by the TCD of the on-line gas chromatograph (GC). Liquid products such as benzene, toluene, ethylbenzene, and styrene were collected each $30 \mathrm{~min}$ and analyzed by the FID of the GC. Conversion of ethylbenzene, X (EB), yield of styrene, Y (ST) and styrene selectivity, S (ST) are expressed as $\mathrm{mol} \%$ on a carbon atom basis.

\section{Results and Discussion}

Figure 1 represents the catalytic behaviors of $\mathrm{VSb} / \mathrm{Al}$ in the different mode of the EBDH reactions. For all reactions, styrene is predominantly observed together with the unreacted EB in the condensate. Only small amounts of benzene and toluene are obtained as by-products. Hydrogen as a major product and methane as a minor one are obtained in the gas phase. Water, $\mathrm{CO}$, and $\mathrm{CO}_{2}$ are also reaction products under the $\mathrm{CO}_{2}-\mathrm{EBDH}$ and $\mathrm{O}_{2}-\mathrm{EBDH}$.

Under inert nitrogen, the catalyst reveals initially, at $1 \mathrm{~h}$ on-stream, high activity, $\mathrm{X}(\mathrm{EB})=73.1 \%$ with good styrene selectivity, $\mathrm{S}(\mathrm{ST})=93.6 \%$. The activity increases slightly until $2.5 \mathrm{~h}$ on-stream and then decreases significantly. The catalyst deactivation is believed to stem mainly from the coke formation as well as deep reduction of $\mathrm{V}^{5+}$ because intense $\mathrm{CO}_{\mathrm{x}}$ evolution was monitored during the reoxidation of the spent catalyst in air stream and then the activity was fully recovered again.

Under steam diluent, the catalyst exhibits rather low activity, $\mathrm{X}(\mathrm{EB})<60 \%$, and poor selectivity, $\mathrm{S}(\mathrm{ST})<85 \%$, as compared with those under nitrogen diluent. Poor selectivity

(a)

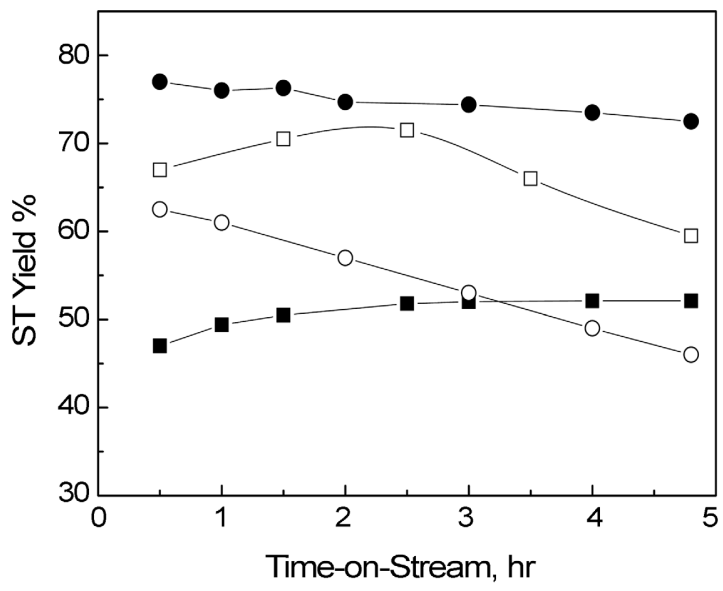

(b)

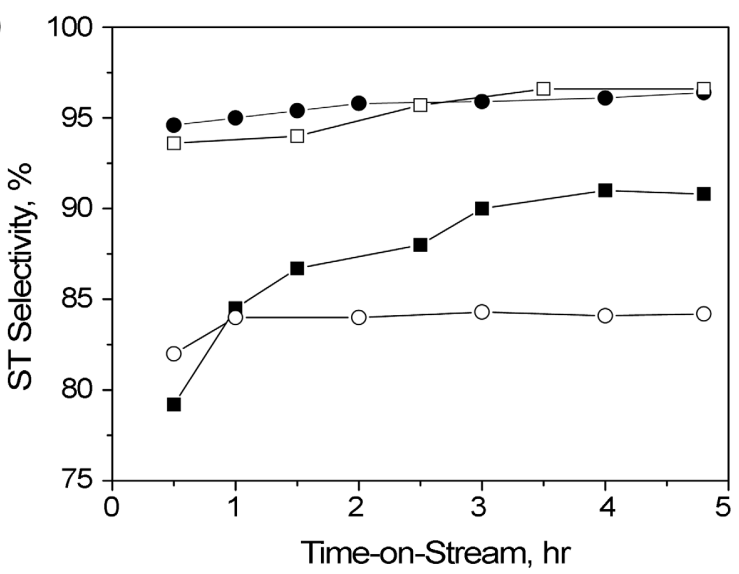

Figure 1. Effect of atmosphere on styrene yield (a) and styrene selectivity (b) in the EBDH under different carrier gas over VSb/Al catlayst. Reaction conditions: $595^{\circ} \mathrm{C}$, LHSV $=1 \mathrm{~h}^{-1}$. Molar ratio of carrier gas and ethylbenzene: $\mathrm{N}_{2} / \mathrm{EB}=12.8$, steam/EB $=10, \mathrm{O}_{2} / \mathrm{EB}$ $=1$, and $\mathrm{CO}_{2} / \mathrm{EB}=1$. Symbols: $(\bullet) \mathrm{CO}_{2},(\square) \mathrm{N}_{2},(\bigcirc) \mathrm{O}_{2},(\boldsymbol{\square})$ $\mathrm{H}_{2} \mathrm{O}$. 
in the presence of steam might be due to the enhancement of hydrocracking or steam reforming reaction of ethylbenzene because a significant amount of methane was observed in the gas phase together with $\mathrm{CO}$. The activity increases initially but remains stable after $2.5 \mathrm{~h}$ on-stream different from under nitrogen. No coke was observed on the surface of the spent catalyst. Such catalytic behavior is similar to the continuous long-term operations with potassium-promoted iron oxide catalyst of the industrial steam-EBDH process. $^{25,46}$ The role of steam in the industrial steam-EBDH process is known to prevent oligomerization of styrene to coke precursors upon desorption of styrene on catalyst surface as well as to facilitate the gasification of the already formed coke with steam reforming reaction..$^{22,25,46}$ Likewise the similar role of steam in the present case appears to take place on the $\mathrm{VSb} / \mathrm{Al}$ catalyst so as to inhibit the carbon accumulation.

In the presence of oxygen, the initial catalytic activity is similar to that under nitrogen diluent, while the activity decreases rapidly with a same deactivation trend as in the nitrogen atmosphere according to time-on-stream. Oxygen conversion was about $95 \%$ but noticeable amounts of unreacted $\mathrm{O}_{2}$ were, nevertheless, detected outlet. In this case, the styrene selectivity, $\mathrm{S}(\mathrm{ST})=82.8 \%$ at $1 \mathrm{~h}$ on stream, becomes lower than that under nitrogen diluent due to the non-selective oxidation of ethylbenzene to form $\mathrm{CO}$ and $\mathrm{CO}_{2}$. As a result, the styrene yield significantly decreased (Fig. 1). Low styrene selectivity caused by essential hydrocarbon over-oxidation to $\mathrm{CO}_{\mathrm{x}}$ has been generally known in the $\mathrm{O}_{2}-\mathrm{EBDH}$ process: $\mathrm{Ni}-\mathrm{V}-\mathrm{Sb}-\mathrm{O} / \mathrm{Al}_{2} \mathrm{O}_{3},{ }^{47} \mathrm{Ce}$ phosphate (at $600{ }^{\circ} \mathrm{C}$ ) and $\mathrm{V}-\mathrm{Mg}-\mathrm{O}$ (at $480{ }^{\circ} \mathrm{C}$ ). ${ }^{25} \mathrm{Un}-$ expectedly, a large amount of hydrogen was observed in the gas phase of the $\mathrm{O}_{2}-\mathrm{EBDH}$, indicating a large contribution of the simple EBDH even in the presence of oxygen. At higher $\mathrm{O}_{2}$-concentration $\left(\mathrm{O}_{2} / \mathrm{EB}=2\right)$, the same was observed at even lower styrene selectivity (not presented here). For this reason, fast catalyst deactivation was found to be unavoidable in the presence of oxygen over $\mathrm{VSb} / \mathrm{Al}$ catalyst despite that $\mathrm{O}_{2}$ is known to be strong oxidant for coke burning. ${ }^{48}$ Like under nitrogen diluent, the subsequent re-oxidation of the catalyst spent in the $\mathrm{O}_{2}$-EBDH has completely restored its initial activity since the coke deposited on the catalyst during the $\mathrm{O}_{2}$-EBDH test was burned out very easily in the absence of ethylbenzene.

Under carbon dioxide, the catalyst exhibits the highest styrene yield (up to $75 \%$ ) and styrene selectivity (up to $97 \%$ ) along with the relatively stable catalytic performance among carrier gases studied. Coke was also observed on the surface

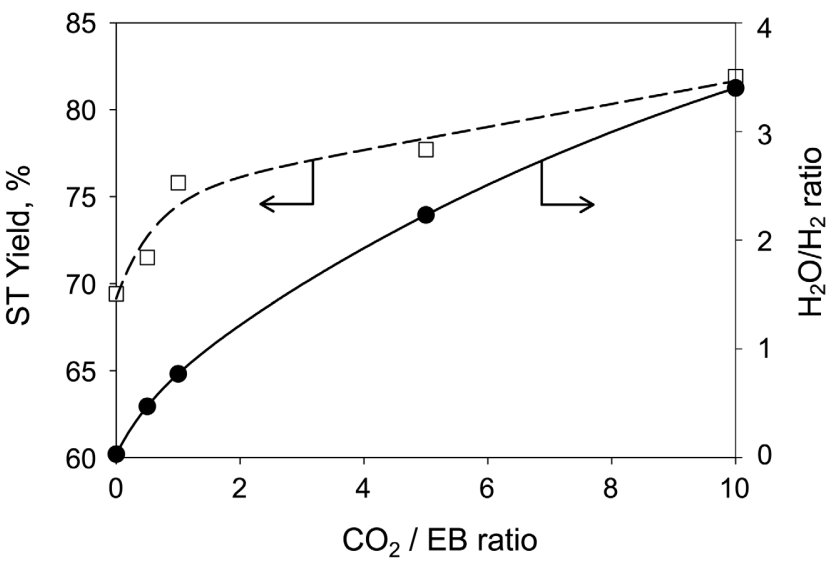

Figure 2. Styrene yields and $\mathrm{H}_{2} \mathrm{O} / \mathrm{H}_{2}$ molar ratios over $\mathrm{VSb} / \mathrm{Al}$ catalyst as functions of $\mathrm{CO}_{2} / \mathrm{EB}$ molar ratio in the reaction mixture. Reaction conditions: $\mathrm{T}=595^{\circ} \mathrm{C}$, LHSV $=1 \mathrm{~h}^{-1}$.

of the spent catalyst but its subsequent re-oxidation in flow of air was accompanied by much lower amount of $\mathrm{CO}_{\mathrm{x}}$ evolution than in cases of simple EBDH and $\mathrm{O}_{2}-\mathrm{EBDH}$. As the molar ratio of $\mathrm{CO}_{2} / \mathrm{EB}$ in the reaction feed increases, the catalytic activity increases (Fig. 2). At $\mathrm{CO}_{2} / \mathrm{EB}=10$ and 595 ${ }^{\circ} \mathrm{C}$, the styrene yield is $81.9 \%$, which is increased by $12.5 \%$, i.e. by $18 \%$ in relative as compared with that under nitrogen diluent. It is noteworthy that the molar ratio of $\mathrm{H}_{2} \mathrm{O} / \mathrm{H}_{2}$ reflecting the correlation between oxidative $\mathrm{CO}_{2}-\mathrm{EBDH}$ with formation of water and non-oxidative dehydrogenation of ethylbenzene with formation of $\mathrm{H}_{2}$ increases almost linearly with an increase of $\mathrm{CO}_{2} / \mathrm{EB}$ ratio. These results unambiguously indicate that the addition of carbon dioxide into the reaction mixture leads to the profound effect on the catalyst activity and stability in parallel with the increase of contribution to the oxidative dehydrogenation route at the expense of the non-oxidative dehydrogenation.

The physicochemical properties of $\mathrm{VSb} / \mathrm{Al}$ catalyst before and after the $\mathrm{CO}_{2}$-EBDH reaction for $12 \mathrm{~h}$ are summarized in Table 1 . The fresh catalyst does not contain crystalline $\mathrm{V}_{2} \mathrm{O}_{5}$-type phases, but the XRD pattern of the fresh catalyst points to the presence of a mixed vanadium-antimony oxide phase, which is assignable to $\mathrm{V}_{1.1} \mathrm{Sb}_{0.9} \mathrm{O}_{4}$ by the appearance of a noticeable peak at $2 \Theta=26.687^{\circ}(47-1496$ file in the JCPDS database). This phase remains unchanged in the used catalyst. The BE of $\mathrm{V} 2 \mathrm{p}_{3 / 2}(517.2-517.6 \mathrm{eV})$ for the fresh catalyst are corresponded to $\mathrm{V}^{5+}$ species [49]. The BE of $\mathrm{V}$ $2 \mathrm{p}_{3 / 2}$ peak remains almost unchanged after catalytic measurement, but the full width at half maximum (FWHM) of the peak slightly increases. The deconvolution result of $\mathrm{V} 2 \mathrm{p}_{3 / 2}$

Table 1. Physicochemical properties of $\mathrm{V}_{0.43} \mathrm{Sb}_{0.57} \mathrm{O}_{\mathrm{x}} / \mathrm{Al}_{2} \mathrm{O}_{3}$ catalyst ${ }^{a}$

\begin{tabular}{|c|c|c|c|c|c|c|c|c|c|c|c|c|}
\hline \multirow{2}{*}{$\begin{array}{c}\text { Catalyst } \\
\text { State }\end{array}$} & \multirow{2}{*}{$\begin{array}{l}\mathrm{S}_{\mathrm{BET}}, \\
\mathrm{m}^{2} / \mathrm{g}\end{array}$} & \multirow{2}{*}{$\begin{array}{l}\text { XRD } \\
\text { Phase }\end{array}$} & \multicolumn{2}{|c|}{$\mathrm{V} 2 \mathrm{p}_{3 / 2}$} & \multicolumn{2}{|c|}{$\mathrm{Sb} 3 \mathrm{~d}_{3 / 2}$} & \multicolumn{3}{|c|}{$\mathrm{V}^{5+}$} & \multicolumn{3}{|c|}{$\mathrm{V}^{4+}$} \\
\hline & & & $\mathrm{BE}$ & FWHM & $\mathrm{BE}$ & FWHM & $\mathrm{BE}$ & FWHM & $\%$ & $\mathrm{BE}$ & FWHM & $\%$ \\
\hline Fresh & 87 & $\mathrm{~V}_{1.1} \mathrm{Sb}_{0.9} \mathrm{O}_{4}$ & 517.6 & 2.18 & 540.2 & 2.34 & 517.6 & 2.18 & 100 & & & \\
\hline Used* & 88 & $\mathrm{~V}_{1.1} \mathrm{Sb}_{0.9} \mathrm{O}_{4}$ & 517.7 & 2.34 & 540.2 & 2.07 & 517.8 & 2.80 & 83.9 & 516.0 & 2.80 & 16.1 \\
\hline
\end{tabular}

$\overline{\mathrm{BE}}$, binding energy (eV); FWHM, full width at half maximum (eV). ${ }^{*}$ Used catalyst: after $12 \mathrm{~h}$ reaction at $\mathrm{T}=595{ }^{\circ} \mathrm{C}, \mathrm{LHSV}=1 \mathrm{~h}^{-1}, \mathrm{CO} / \mathrm{EB}^{2}=1$ (molar ratio). 


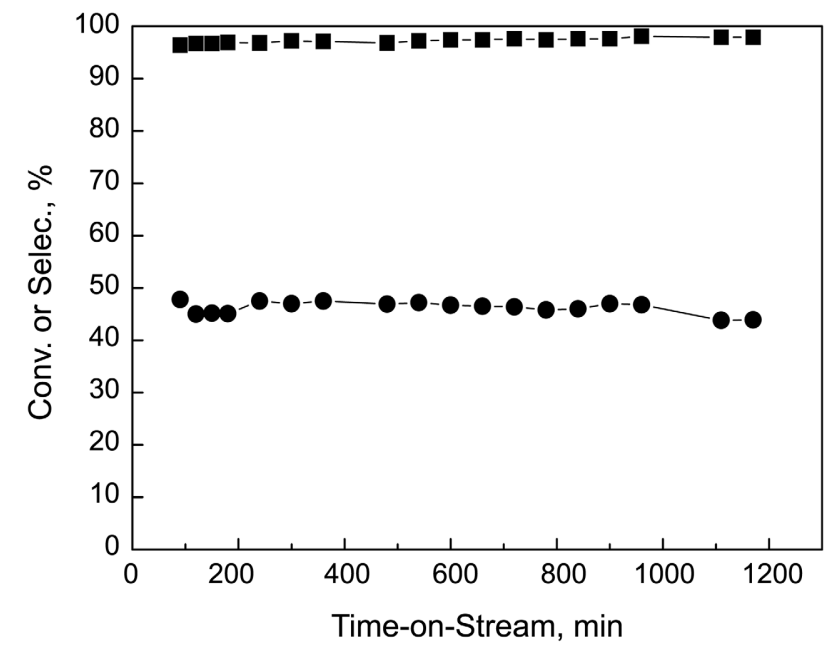

Figure 3. Stability of $\mathrm{V}_{0.43} \mathrm{Sb}_{0.57} \mathrm{O}_{\mathrm{x}} / \mathrm{Al}_{2} \mathrm{O}_{3}$ catalyst in the $\mathrm{CO}_{2}$ EBDH reaction. Reaction conditions: $\mathrm{T}=550{ }^{\circ} \mathrm{C}, \mathrm{EB} / \mathrm{CO}_{2}=1$ $\left(\right.$ molar ratio), LHSV $=1 \mathrm{~h}^{-1}$. Symbols: $(\bullet)$ ethylbenzene conversion, ( $\mathbf{\square})$ styrene selectivity.

peak points out that the surface oxidation state of the used $\mathrm{VSb} / \mathrm{Al}$ catalyst is predominantly reduced from $\mathrm{V}^{5+}$ to $\mathrm{V}^{4+}$ and practically does not contain $\mathrm{V}^{3+}$ species as the deeply reduced oxidation state. The $\mathrm{BE}$ of $\mathrm{Sb} 3 \mathrm{~d}_{3 / 2}$ in the fresh catalyst indicates the $\mathrm{Sb}^{5+}$ species $^{49}$ and its parameter remains unchanged after catalytic run.

Figure 3 shows on-stream activity of the $\mathrm{VSb} / \mathrm{Al}$ catalyst at $550{ }^{\circ} \mathrm{C}$. Much improved catalyst stability has been achieved at lower reaction temperature in comparison with catalyst performance at $595^{\circ} \mathrm{C}$ (Fig. 1). This stability is also confirmed by unchanged specific surface area after reaction (Table 1 ). The catalyst activity could be easily reactivated without a loss of styrene yield by means of short-term treatment in an air stream.

Figure 4 presents the effect of reaction temperature for the $\mathrm{CO}_{2}-\mathrm{EBDH}$ at $\mathrm{CO}_{2} / \mathrm{EB}=5$. The catalytic activity was compared with those calculated at equilibrium of the steam$\mathrm{EBDH}$ and $\mathrm{CO}_{2}$-EBDH. The styrene yield increases almost linearly with increasing of reaction temperature ranging from 510 to $610^{\circ} \mathrm{C}$. The slope of the measured activity curve with reaction temperature was actually higher than that at equilibrium of the simple EBDH. So, it is highlighted that in the presence of $\mathrm{CO}_{2}$ the catalyst exhibits at reaction temperatures between $560-610{ }^{\circ} \mathrm{C}$ the supra-equilibrium conversions of ethylbenzene as compared with those at equilibrium of the non-oxidative steam-EBDH in the absence of $\mathrm{CO}_{2}$. This result implies the possible role of $\mathrm{CO}_{2}$ as an oxidant. However, over $\mathrm{VSb} / \mathrm{Al}$ catalyst, the activation of $\mathrm{CO}_{2}$ needs rather high temperature, and this effect becomes apparent only at reaction temperatures $>550{ }^{\circ} \mathrm{C}$.

The catalytic activity of the VSb/Al in the $\mathrm{CO}_{2}$-EBDH is mainly determined by the supported vanadium oxide species whereas the presence of $\mathrm{SbO}_{\mathrm{x}}$ positively affects the catalyst stability through the facilitation of the redox cycle as evidenced by $\mathrm{H}_{2}$-TPR and subsequent $\mathrm{CO}_{2}$-pulse reoxidation to confirm the vanadium redox cycle in the previous

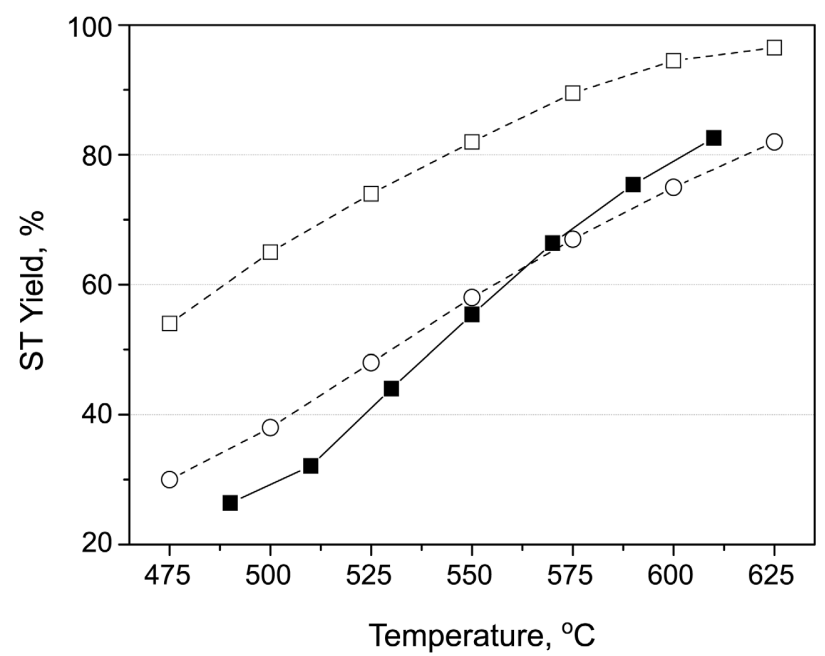

Figure 4. Thermodynamic equilibrium of $(\square) \mathrm{CO}_{2}-\mathrm{EBDH},(\bigcirc)$ steam-EBDH and ( $\boldsymbol{\square})$ experimental results in the $\mathrm{CO}_{2}$-EBDH over VSb/Al catalyst. Reaction conditions: EB-LHSV $=1 \mathrm{~h}^{-1}, \mathrm{CO}_{2} / \mathrm{EB}$ $=5$.

work. ${ }^{44}$ In this cycle, styrene formation from ethylbenzene in the reduction step on $\mathrm{V}^{5+}$-containing active site produces a reduced V-site with oxygen vacancy, which is then reoxidized by carbon dioxide. A vanadium component of the catalyst in the steady state practically tends to keep the high oxidation state in the $\mathrm{CO}_{2}$-EBDH reaction. For instance, the average value of surface vanadium oxidation state was estimated to be 4.84 after the $\mathrm{CO}_{2}$-EBDH run of $12 \mathrm{~h}$ onstream according to the deconvolution of XPS peaks. ${ }^{44}$

One of principal reasons causing the coke formation seems to be the non-optimal over-reduction of active V-sites under the reaction conditions. The effective redox cycle of the supported vanadium oxide catalysts for the $\mathrm{CO}_{2}-\mathrm{EBDH}$ would be likely to occur only between $\mathrm{V}^{5+}$ and $\mathrm{V}^{4+}$. Accumulation of $\mathrm{V}^{3+}$ species represents one mode of catalyst deactivation ${ }^{50}$ because the re-oxidation of deeply reduced $\mathrm{V}^{3+}$ - centers could become the rate-limiting step as it was evidenced for the oxydehydrogenation of ethane over $\mathrm{V}_{2} \mathrm{O}_{5} /$ $\mathrm{Al}_{2} \mathrm{O}_{3}$ catalyst. ${ }^{51}$ In the propane ammoxidation on $\mathrm{V}-\mathrm{Sb}-\mathrm{O}$ catalyst, the reduced supra-surface vanadium oxide species with relatively low reoxidizability is responsible for the unselective conversion of propane to $\mathrm{CO}_{\mathrm{x}} \cdot{ }^{29}$ Meanwhile, carbon oxides are usually formed from strongly adsorbed organic intermediates similar to coke precursors. ${ }^{52}$ Coke formation under the oxydehydrogenation of n-butane occurs faster on reduced V-Mg-O catalyst than on the fully oxidized one. $^{53}$ Taking into account that EB is much stronger reductant than light paraffins mentioned above, ${ }^{28}$ adsorption of EB on non-properly regenerated active sites could hamper the redox cycle and, as a consequence, become the reason to increase coke formation and deactivation of the catalyst.

On vanadium oxide-based catalysts, Mars-van Krevelen redox mechanism has been generally accepted in the literature for selective oxidations of different hydrocarbons, including $\mathrm{O}_{2}$-EBDH: ${ }^{26,28,35,54}$ 


\begin{tabular}{ll}
\hline & $\mathrm{N}$ \\
\hline $\mathrm{ZO}+\mathrm{PhCH}_{2} \mathrm{CH}_{3} \rightarrow \mathrm{Z}+\mathrm{PhCH}=\mathrm{CH}_{2}+\mathrm{H}_{2} \mathrm{O}$ & 2 reduction stage 1 \\
$\mathrm{Z}+\mathrm{O}_{2} \rightarrow \mathrm{ZO}_{2}$ & 1 re-oxidation stage 2a \\
$\mathrm{ZO}_{2}+\mathrm{Z} \rightarrow 2 \mathrm{ZO}$ & 1 re-oxidation stage 2b \\
\hline $2 \mathrm{PhCH}_{2} \mathrm{CH}_{3}+\mathrm{O}_{2} \rightarrow 2 \mathrm{PhCH}=\mathrm{CH}_{2}+2 \mathrm{H}_{2} \mathrm{O}$ &
\end{tabular}

where $\mathrm{N}$ is stoichiometric number of a stage; $\mathrm{Z}$ is a reduced $\mathrm{V}$ - site; $\mathrm{ZO}_{2}$ and $\mathrm{ZO}$ are $\mathrm{V}$-sites re-oxidized by, respectively, molecular and atomic form of oxygen chemisorbed.

In the case of EBDH under inert carrier gas, non-oxidative dehydrogenation naturally dominates, but at an initial stage oxidative dehydrogenation as well as total oxidation of ethylbenzene also occur at the certain extent by means of lattice oxygen species in the catalyst although its contribution decreases rapidly due to the absence of gas-phase oxygen needed for the re-oxidation of oxygen vacancies.

For the $\mathrm{CO}_{2}$-EBDH over supported vanadium oxide catalyst, the redox mechanism could be reasonably proposed based on their characterization results ${ }^{44}$ as follows:

\begin{tabular}{ll}
\hline & $\mathrm{N}$ \\
\hline $\mathrm{ZO}+\mathrm{PhCH}_{2} \mathrm{CH}_{3} \rightarrow \mathrm{Z}+\mathrm{PhCH}=\mathrm{CH}_{2}+\mathrm{H}_{2} \mathrm{O}$ & 1 reduction stage 1 \\
$\mathrm{Z}+\mathrm{CO}_{2} \rightarrow \mathrm{ZO}+\mathrm{CO}$ & 1 re-oxidation stage 2 \\
\hline $\mathrm{PhCH}_{2} \mathrm{CH}_{3}+\mathrm{CO}_{2} \rightarrow \mathrm{PhCH}=\mathrm{CH}_{2}+\mathrm{CO}+\mathrm{H}_{2} \mathrm{O}$ & \\
\hline
\end{tabular}

In this work, catalytic behaviors under oxygen and carbon dioxide atmospheres point out that oxygen is not able to regenerate properly some sorts of the catalytically active sites on the supported vanadium oxide catalysts as compared with carbon dioxide. As it was known for vanadium oxidebased catalysts, ${ }^{28,54}$ the catalyst re-oxidation comprises chemisorption of an oxygen molecule and its dissociation with the electron transfer according to the following sequence:

$$
\mathrm{O}_{2}+\mathrm{e} \rightarrow \mathrm{O}_{2}^{-}+\mathrm{e} \longrightarrow 2 \mathrm{O}^{-}+2 \mathrm{e} \longrightarrow 2 \mathrm{O}^{2-}
$$

In order to form the atomic lattice oxygen $\left(\mathrm{O}^{2-}\right)$, which is active for oxidative dehydrogenation of hydrocarbons, at least two oxygen vacancies in the vicinity might be necessary for the dissociative chemisorption of an oxygen molecule. However, the isolated reduced sites are favorable for the formation of a molecularly electrophilic adsorbed form, $\mathrm{O}_{2}{ }^{-}$, which is usually considered to be responsible for the total oxidations of olefinic hydrocarbons. ${ }^{28,54}$ These circumstances might explain both nonselective oxidation of ethylbenzene and unstable catalytic performance in the $\mathrm{O}_{2}$ EBDH reaction. It is obvious that a high surface coverage by the hydrocarbon should geometrically limit a number (or density) of accessible sites for oxygen chemisorption and catalyst re-oxidation. ${ }^{22}$ The deficit of pair neighboring oxygen vacancies can hinder their re-oxidation step with dioxygen, probably because of the surface coverage of large ethylbenzene molecules. In contrast, carbon dioxide might be adsorbed dissociatively on an accessible single site of reduced vanadium species if the catalyst surface prefers perpendicular adsorption of $\mathrm{CO}_{2}$. In this case, oxygen species generated from $\mathrm{CO}_{2}$ molecules can re-oxidize the reduced vanadium sites and keep the surface vanadium species at high oxidation state, resulting in improving the catalyst performance.

Therefore, the presented results obtained for the EBDH under different atmospheres over the $\mathrm{V}_{0.43} \mathrm{Sb}_{0.57} \mathrm{O}_{\mathrm{x}} / \mathrm{Al}_{2} \mathrm{O}_{3}$ catalyst reveal advantages of the EBDH process using carbon dioxide as oxidant as compared with the nonoxidative EBDH and the oxidative process in the presence of oxygen.

\section{Conclusions}

The ethylbenzene dehydrogenation over the $\mathrm{V}_{0.43} \mathrm{Sb}_{0.57} \mathrm{O}_{\mathrm{x}} /$ $\mathrm{Al}_{2} \mathrm{O}_{3}$ catalyst was investigated under different carrier gas such as inert nitrogen, steam, oxygen or carbon dioxide. Among carrier gases, carbon dioxide was utilized as the selective and soft oxidant through an oxidative pathway of the EBDH, leading to the highest catalytic activity and styrene selectivity along with the relatively stable catalytic performance. Moreover, it is highlighted that the catalyst showed supra-equilibrium conversions of ethylbenzene at specific reaction conditions in the presence of $\mathrm{CO}_{2}$ as compared to those at equilibrium of the non-oxidative steam-EBDH in the absence of $\mathrm{CO}_{2}$.

Acknowledgements. This work was performed for the Greenhouse Gas Research Center, one of the Critical Technology-21 Programs, funded by the Ministry of Science and Technology of Korea (MOST). VPV thanks the Korean Ministry of Science and Technology for the visiting scientist fellowship.

\section{References}

1. Inui, T.; Anpo, M.; Izui, K.; Yanagida, S.; Yamaguchi, T. Stud. Sur. Sci. Catal. 1998, 114, 114.

2. Denise, B.; Sneeden, R. P. A. Chem. Technol. 1982, 108.

3. Aresta, M.; Fragale, C.; Quaranta, E.; Tommasi, I. J. J. Chem. Soc., Chem. Commun. 1992, 315.

4. Krylov, O. V.; Mamedov, A. Kh. Ind. Eng. Chem. Res. 1995, 34, 474.

5. Park, S.-E.; Chang, J.-S.; Yoo, J. S. In Environmental Challenges and Greenhouse Gas Control for Fossil Fuel Utilization in the $21^{s t}$ Century; Maroto-Valer, M. M., Soong, Y., Song, C., Eds.; Kluwer Academic/Plenum Publishers: New York, 2001; p 359.

6. Nishiyama, T.; Aika, K. J. Catal. 1990, 122, 346.

7. Yoo, J. S. Catal. Today 1998, 41, 409.

8. Park, S.-E.; Chang, J.-S.; Park, M. S. Prepr. Am. Chem. Soc., Div. Fuel Chem. 1996, 41, 1387.

9. Sugino, M.; Shimada, H.; Turuda, T.; Miura, H.; Ikenaga, N.; Suzuki, T. Appl. Catal. A 1995, 121, 125.

10. Mimura, N.; Saito, M. Catal. Today 2000, 55, 173.

11. Mimura, N.; Takahara, I.; Saito, M.; Sasaki, Y.; Murata, K. Catal. Lett. 2002, 78, 125.

12. Badstube, T.; Papp, H.; Dziembaj, R.; Kustrowski, P. Appl. Catal. A 2000, 204, 153.

13. Sakurai, Y.; Suzaki, T.; Ikenaga, N.; Suzuki, T. Appl. Catal. A 2000, 192, 281

14. Ikenaga, N.; Tsuruda, T.; Senma, K.; Yamaguchi, T.; Sakurai, Y.; 
Suzuki, T. Ind. Eng. Chem. Res. 2000, 39, 1228.

15. Sakurai, Y.; Suzaki, T.; Nakagawa, K.; Ikenaga, N.; Aota, H.; Suzuki, T. J. Catal. 2002, 209, 16.

16. Chang, J.-S.; Park, S.-E.; Park, M. S. Chem. Lett. 1997, 26, 1123 .

17. Noh, J.; Chang, J.-S.; Park, J.-N.; Lee, K. Y.; Park, S.-E. Appl. Organomet. Chem. 2000, 14, 815.

18. Park, J.-N.; Noh, J.; Chang, J.-S.; Park, S.-E. Catal. Lett. 2000, 65, 75.

19. Chang, J.-S.; Noh, J. I.; Park, S.-E.; Kim, W. Y.; Lee, C. W. Bull. Korean Chem. Soc. 1998, 19, 1342.

20. Chang, J.-S.; Park, M. S.; Vislovskiy, V. P.; Park, S.-E.; Yoo, J. S. Prepr. Am. Chem. Soc., Div. Fuel Chem. 2002, 47, 309.

21. Vislovskiy, V. P.; Chang, J.-S.; Park, M. S.; Park, S.-E. Catal. Commun. 2002, 3, 227.

22. Centi, G.; Perathoner, S. Catal. Today 1998, 41, 457.

23. Xue, E.; Ross, J. R. H.; Mallada, R.; Menendez, M.; Santamaria, J.; Perregard, J.; Nielsen, P. E. H. Appl. Catal. A 2001, 210, 271.

24. Mimura, N.; Takahara, I.; Saito, M.; Hattori, T.; Ohkuma, K.; Ando, M. Catal. Today 1998, 45, 61.

25. Cavani, F.; Trifiro, F. Appl. Catal. A 1995, 133, 219.

26. Mamedov, E. A.; Corberan, V. C. Appl. Catal. A 1995, 127, 1.

27. Rizayev, R. G.; Mamedov, E. A.; Vislovskii, V. P.; Sheinin, V. E. Appl. Catal. A 1992, 83, 103.

28. Grzybowska-Swierkosz, B. Appl. Catal. A 1997, 157, 409.

29. Centi, G.; Perathoner, S.; Trifiro, F. Appl. Catal. A 1997, 157, 143.

30. Vislovskiy, V. P.; Bychkov, V. Y.; Sinev, M. Y.; Shamilov, N. T.; Ruiz, P.; Schay, Z. Catal. Today 2000, 61, 325.

31. Vislovskiy, V. P.; Shamilov, N. T.; Sardarly, A. M.; Bychkov, V. Yu.; Sinev, M. Yu.; Ruiz, P.; Valenzuela, R. X.; Corberan, V. C. Chem. Eng. J. 2003, 95, 37.

32. Belomestnykh, I. P.; Skrigan, E. A.; Rozhdestvenskaya, N. N.; Isaguliants, G. V. Stud. Surf. Sci. Catal. 1992, 72, 453.

33. Hanuza, J.; Jezowska-Trzebiatowska, B.; Oganowski, W. J. Mol. Catal. 1985, 29, 109.

34. Chang, W. S.; Chen, Y. Z.; Yang, B. L. Appl. Catal. A 1995, 124,
221

35. Mamedov, E. A.; Talyshinskii, R. M.; Rizayev, R. G.; Fierro, J. L. G.; Corberan, V. C. Catal. Today 1996, 32, 177.

36. Hirano, T. Appl. Catal. 1986, 26, 81 .

37. Sato, S.; Ohhara, M.; Sodesawa, T.; Nozaki, F. Appl. Catal. 1988 , 37, 207.

38. Ye, X.; Hua, W.; Yue, Y.; Dai, W.; Miao, C.; Xie, Z.; Gao, Z. New J. Chem. 2004, 28, 373.

39. Saito, M.; Kimura, H.; Mimura, N.; Wu, J.; Murata, K. Appl. Catal. A 2003, 239, 71.

40. Dziembaj, R.; Kuœtrowski, P.; Chmielarz, L. Appl. Catal. A 2003, 255,35

41. Sun, A.; Qin, Z.; Wang, J. Appl. Catal. A 2002, 234, 179.

42. Sun, A.; Qin, Z.; Chen, S.; Wang, J. J. Mol. Catal. A: Chem. 2004, 210,189 .

43. Carja, G.; Nakamura, R.; Aida, T.; Niiyama, H. J. Catal. 2003, 218,104

44. Park, M.-S.; Vislovskiy, V. P.; Chang, J.-S.; Shul, Y.-G.; Yoo, J. S.; Park, S.-E. Catal. Today 2003, 87, 205.

45. Chang, J.-S.; Vislovskiy, V. P.; Park, M.-S.; Hong, D.-Y.; Yoo, J. S.; Park, S.-E. Green Chem. 2003, 5, 587.

46. Zhu, X. M.; Schön, M.; Bartmann, U.; van Veen, A. C.; Muhler, M. Appl. Catal. A 2004, 266, 99.

47. Aliyev, V. S.; Talyshinskii, R. M. et al. USSR Pat. 1,234,397, 1986.

48. Bartholomew, C. H. Chem. Eng. 1984, $91,96$.

49. Moulder, J. F. et al. Handbook of X-ray Photoelectron Spectroscopy; Perkin-Elmer Corp.: 1995.

50. Wang, D.; Kung, H. H.; Barteau, M. A. Appl. Catal. A 2000, 201, 203.

51. Bars, J. L.; Auroux, A.; Forissier, M.; Vedrine, J. C. J. Catal. 1996, 162, 250.

52. Datka, J.; Sarbak, Z.; Eischens, R. P. J. Catal. 1994, 145, 544.

53. Tellez, C.; Abon, M.; Dalmon, J. A.; Mirodatos, C.; Santamaria, J. J. Catal. 2000, 195, 113.

54. Bielanski, A.; Najbar, M. Appl. Catal. A 1997, 157, 223. 